\title{
CAG and GGN Repeat Length Polymorphisms of Androgen Receptor Gene in Women with Breast Cancer: A Case-Control Study from South India
}

\author{
Durgadatta Tosh ${ }^{1}$, Bineet Panda ${ }^{1}$, Tipirisetti Nageswar Rao ${ }^{2}$, Arvind Babu ${ }^{1}$, Vishnupriya Satti ${ }^{2}$, \\ Digumarti Raghnadharao ${ }^{3}$, Lalji Singh ${ }^{1}$, Lakshmi Rao ${ }^{{ }^{*}}$ \\ ${ }^{1}$ Centre for Cellular and Molecular Biology, Hyderabad, India; ${ }^{2}$ Department of Genetics, Osmania University, Hyderabad, India; \\ ${ }^{3}$ Department of Medical Oncology, Nizams Institute of Medical Sciences, Hyderabad, India. \\ Email: *lakshmi@ccmb.res.in
}

Received April 17 ${ }^{\text {th }}, 2012$; revised May $22^{\text {th }}, 2012$; accepted June $13^{\text {th }}, 2012$

\begin{abstract}
Aim: The Androgen Receptor (AR) is a ligand-dependent transcriptional activator and the $A R$ gene contains a highly polymorphic trinucleotide repeat CAG and GGN in the first exon. Given the lack of information AR-CAG and GGN repeat polymorphism and its potential correlation with breast cancer in South Indian women, we conducted a case-control study to observe the effects of CAG \& GGN repeat length polymorphism and risk of breast cancer. Methods: Polymorphisms for AR-CAG and GGN repeat length was detected by Gene Scan analysis in the genomic DNA from cases with breast cancer and controls. Results: Association between $A R$ genotype was calculated by categorising alleles as short (S) and long (L) and taking median value as the cut-off. LL genotype of CAG repeat was found to be associated with breast cancer (OR, 4.58; 95\% CI, $10.61-1.98$; $\mathrm{p}-0.0004)$. GGN repeat having $\geq 21$ was found in most of the cases and none of the cases showed 20 repeats thus indicate that alleles having homozygous repeat 20 may be protective towards breast cancer. Also, SS genotype was observed in $56.84 \%$ of cases and in $73.03 \%$ of controls (OR, $0.48 ; 95 \%$ CI, 0.26 - 0.89; $\mathrm{p}$ value, 0.02). Conclusion: Our results indicate that longer CAG and GGN repeat may be associated with breast cancer whereas, the shorter GGN repeat length genotype of $A R$ are protective.
\end{abstract}

Keywords: Breast Cancer; Androgen Receptor; CAG; GGN

\section{Introduction}

Breast cancer is the most common cancer and the leading cause of the cancer deaths in women today. The incidence of breast cancer varies greatly around the world: it is lowest in less-developed countries, greatest in the more-developed countries and is on the rise especially in developing countries such as India. A recent data showed that India has one of the highest cancer rates in the world [1]. The incidence of breast cancer in India is on the rise and is rapidly becoming the number one cancer in women, pushing the cervical cancer to the second spot. The aetiopathogenesis of breast cancer is largely unknown, but most of the available evidences suggest that it is a multifactorial disease [2]. Exposures to endogenous and exogenous hormones are known to influence breast cancer risk. Androgens, the predominant sex steroid hormones in postmenopausal women, act through the androgen receptor $(A R)$, a member of the steroid receptor subfamily. Among postmenopausal women, androgen lev-

"Corresponding author els appear to be positively associated with breast cancer risk [3], but it is not known whether $A R$ has a role in the mediation of these effects.

Androgen action is mediated at the transcriptional level by the $A R$ in breast cancer cells $[4,5]$. The $A R$ and androgens induce proteins, like prostate-specific antigen (PSA) (98\%) and the gross cystic disease fluid protein-15 (GCDFP-15) (92\%), in the breast cancer specimens, confirming that $A R$ is functionally active in human breast cancer cells [6]. Also, the $A R$ is found to be expressed in $>70 \%$ of breast cancers and has been implicated in breast cancer pathogenesis [7-10]. However, the role of androgens in breast cancer development and carcinogenesis remains unclear $[11,12]$.

The $A R$, which is genetically polymorphic, is codified by the $A R$ gene which is located on the $\mathrm{X}$ chromosome (q 11.2 - q 12). The $A R$ gene spans $90 \mathrm{~kb}$, contains eight exons and encodes for a protein of about 917 amino acids $[13,14]$. The exon 1 of $A R$ gene contains two (microsatellite) trinucleotide repeat polymorphisms, the CAG (encoding for polyglutamine) and the GGN (encoding for 
polyglycine) repeat sequences. These polymorphisms flank the N-terminal domain of $A R$ protein, where the transactivation activity of the protein resides [4].

Several studies have shown the effect of CAG polymorphism on the transactivation capacity of the receptor; the longer the repeat the less efficient the transactivation $[15,16]$, which typically is in the range of 6-39 repeat units. The role of $(\mathrm{CAG})_{\mathrm{n}}$ polymorphism of $A R$ in cancer predisposition is supported by association studies of breast and prostate cancer risk. Variation of the CAG$A R$ length polymorphism shows remarkable differences among diverse ethnic groups [17]. African populations have the shortest CAG repeats, whereas the Asian populations possess the longest, while Caucasians and American Indians have medium number of repeat sequences $[18,19]$. Hence, the predisposition of these populations to $\mathrm{BC}$ is also known to vary accordingly.

The polyglycine tract in the $A R$ protein is encoded by $(\mathrm{CGT})_{3} \mathrm{GGG}(\mathrm{GGT})_{2}(\mathrm{GGC})_{\mathrm{n}}$, an invariant six-glycine tract (GGT/GGG) followed by a polymorphic GGC repeat, that is less polymorphic than CAG repeat [14-20]. About $90 \%$ of normal AR contains $16-18$ CGG repeats.

Most of the experimental studies conducted so far report on the effects of lengthening either of the CAG or the GGN repeats, while the other repeat is maintained as a constant. However, recent observations on diverse human tumors [21,22] suggest that combination of different repeat length in the normal range could increase the risk of developing cancer [6]. Hence, it remains to be determined whether the combined effects of CAG and GGN repeat polymorphism on androgen action are independent or not. Till date, data supporting the relationship between $A R$ polymorphism and $\mathrm{BC}$ came exclusively from America and European countries. Though there are a few reports from Asia on $A R$ polymorphism in $\mathrm{BC}$, there is no data been reported from South India. Therefore, we conducted a case-control study to observe the effects of CAG \& GGN repeat length polymorphism and risk of $\mathrm{BC}$, which could ultimately prove to be useful for the early prognosis of the high risk patients and further management of such individuals.

\section{Materials and Methods}

\subsection{Patient and Control Recruitment}

Ninety-six women with breast cancer of age group 25 79 years were recruited from Department of Medical Oncology, Nizams Institute of Medical Sciences, Hyderabad, India. All the patients were assessed clinically, with complete medical history. Respective consent forms from the patients recruited for the study were collected by the concerned clinic. And eighty nine controls of age group $30-70$ years were randomly selected from the healthy women of general population with no familial history of breast cancer. Recruitment of the controls was entirely ethnically population-based to support the study. The Institutional Review Board of Centre for Cellular and Molecular Biology (CCMB), Hyderabad, approved the study.

\subsection{DNA Extraction}

A 5-ml aliquot of peripheral blood was collected in EDTA vacutainers for genomic DNA isolation. DNA was extracted using the Nucleon BACC2 DNA extraction kit (Amersham Pharmacia Biotech, Piscataway, NJ, USA) according to the manufacturer's protocol.

\subsection{Molecular Analysis and Assessment of the CAG and GGN Repeats}

The CAG repeat region of the $A R$ gene was amplified with a pair of primers, forward:

5'FAM-TCCGAATCTGTTCCAGAGCGTGC-3', reverse: 5'-GCTGTGAAGGTTGCTGTTCCTC-3' flanking the repeat region. PCR reaction mixture consisted of $1.0 \mu \mathrm{l}$ PCR buffer (10X), $1.0 \mu 1 \mathrm{MgCl}_{2}(25 \mathrm{mM}), 1.0 \mu 1 \mathrm{dNTPs}$ $(10 \mathrm{mM}), 1.0 \mathrm{pM}$ of each primer, 0.5 units AmpliTaq Gold $^{\mathrm{TM}}$ DNA polymerase and $20 \mathrm{ng}$ genomic DNA. PCR was done under the following conditions; initial denaturation at $94^{\circ} \mathrm{C}$ for 12 minutes followed by 30 cycles of $94^{\circ} \mathrm{C}$ for 1 minute, $60.5^{\circ} \mathrm{C}$ for 1 minute and $72^{\circ} \mathrm{C}$ for 1 minute with a final extension at $72^{\circ} \mathrm{C}$ for 30 minutes. GGN repeat was amplified with a pair of primers: forward 5'FAM-CCGCTTCCTCATCCTGGCACAC 3' and reverse 5'GCCGCCAGGGTACCACACATC 3' flanking the repeat region. PCR reaction mixture included $1.0 \mu \mathrm{l}$ PCR buffer $(10 \times), 1.0 \mu \mathrm{l} \mathrm{MgCl}(25 \mathrm{mM}), 1.0 \mu \mathrm{l}$ dNTPs (10 mM), $1.0 \mu 1$ DMSO (100\%), $1.0 \mu 1$ glycerol (100\%), $1.0 \mathrm{pM}$ of each primer, 0.5 units Amplitaq Gold DNA polymerase and $20 \mathrm{ng}$ genomic DNA. PCR conditions consisted of denaturation at $96^{\circ} \mathrm{C}$ for 15 minutes, followed by 40 cycles of $96^{\circ} \mathrm{C}$ for 1.5 minutes, $55.5^{\circ} \mathrm{C}$ for 1 minute and $72^{\circ} \mathrm{C}$ for 3 minutes and a final extension at $72^{\circ} \mathrm{C}$ for 20 minutes. For GeneScan, $3.0 \mu 1$ of PCR product was mixed with $0.2 \mu \mathrm{l}$ of LIZ500 and $6.8 \mu \mathrm{l}$ Hi-Di formamide. Upon denaturation for 5 minutes at $96^{\circ} \mathrm{C}$ and cooling for 5 minutes on ice, samples were run on 3730 DNA analyzer (Applied Biosystems, USA). PCR and genotyping were repeated for all samples to confirm the number of repeats. The raw data was further analyzed using GeneMapper software (Applied Biosystems, USA).

\subsection{Statistical Analysis of Results}

Each variable was summarized according to its scale and distribution. The genescan results were analyzed on Gene- 
Mapper 3.1 software to check for CAG and GGN length variations. Statistical significance is reached in all tests when a two tailed $\mathrm{p}<0.05$ was obtained. Main analyses were carried out using the SPSS version 16.0 statistical package from SPSS Inc., Chicago, IL, USA.

\section{Results}

Gene Scan was done for the two-microsatellite regions of $A R$ gene i.e. $\mathrm{CAG}$ and $\mathrm{GGN}$ repeats in all the cases and controls.

\subsection{Gene Scan Results}

In the present study, we have analyzed the association of two polymorphic repeats namely CAG and GGN of the $A R$ gene located in the coding region of the exon 1.

\subsection{Distribution of CAG and GGN Alleles in Cases and Controls}

The frequency distribution of both CAG and GGN repeat alleles in the present study is shown in the table.

The assayed case and control population showed 18 different CAG repeats, ranging from 11 to 28 . Alleles with $11,12,26$ repeats were not present in any of the cases and among all the controls, alleles with 13, 14, 27 repeats were not present. Among all cases, repeat 19 was observed with highest frequency of $13.54 \%$, while in controls, allele with 20 repeats had the highest frequency of $25.28 \%$. The $\mathrm{CAG}$ allelic distribution was near normal (Figure 1).
However, the mean variation in the CAG repeat between cases $($ mean $=20.13)$ and control $($ mean $=19.8)$ was found to be statistically non significant ( $\mathrm{p}$ value$0.83)$.

The GGN repeat ranged from 10 to 25 repeats where no allele was found to have 11 or 14 repeats. The $A R$ allele with 21 GGN repeats was predominant in all cases with a very low frequency of smaller allele distributed between the ranges of 10 to 25 . While $A R$ allele with 20 GGN repeats was predominant in all the control samples, no case having $A R$ allele with 20 GGN repeat was found (Figure 2). $A R$ allele with 21 repeats was found in $68.94 \%$ of the cases whereas, in controls, allele with 20 repeats had the highest frequency of $75.84 \%$ and the rest of the alleles were distributed scarcely among the range of 10 to 25. Apart from this no allele with repeat size of $11,13,14$ and 16 were found in any control sample.

On comparing homozygous repeat of GGN in cases and controls, it was observed that in controls 20 repeat is predominant $(96.30 \%)$ whereas, in cases 21 repeat was found to be predominant $(90.00 \%)$ (Table 1).

\subsection{CAG and GGN Polymorphism and Breast Cancer}

The number of CAG repeats has been proposed to be related to the activity of the receptor, hence we divided the subjects into three subgroups, SS (small small), SL (small long) and LL (long long) genotype by using median value as the cut-off according to the strategy followed by the other reports $[21,23,24]$. For CAG repeat

\section{CAG Repeat}

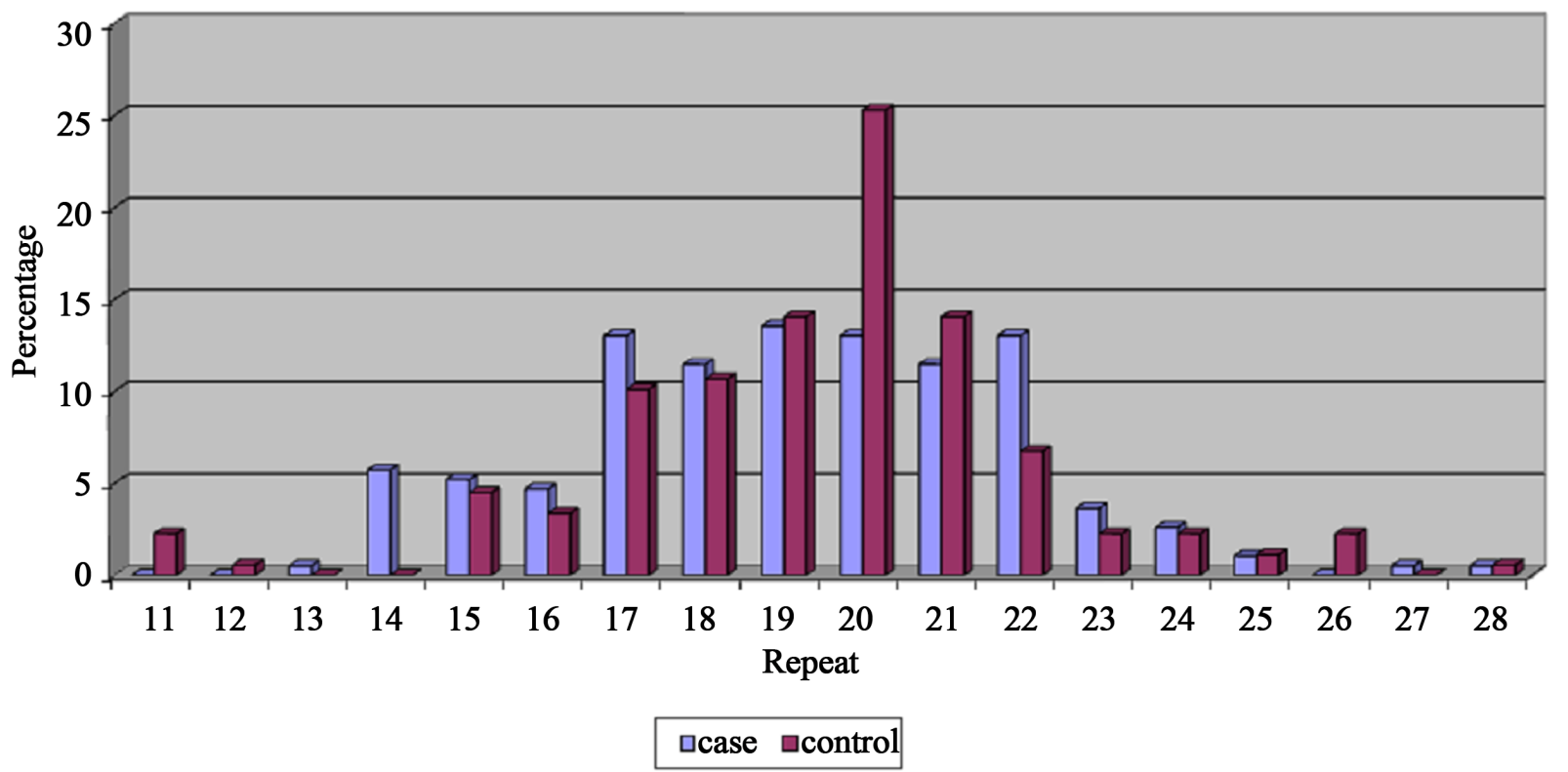

Figure 1. Distribution of CAG repeats of $A R$ gene in women with breast cancer. 


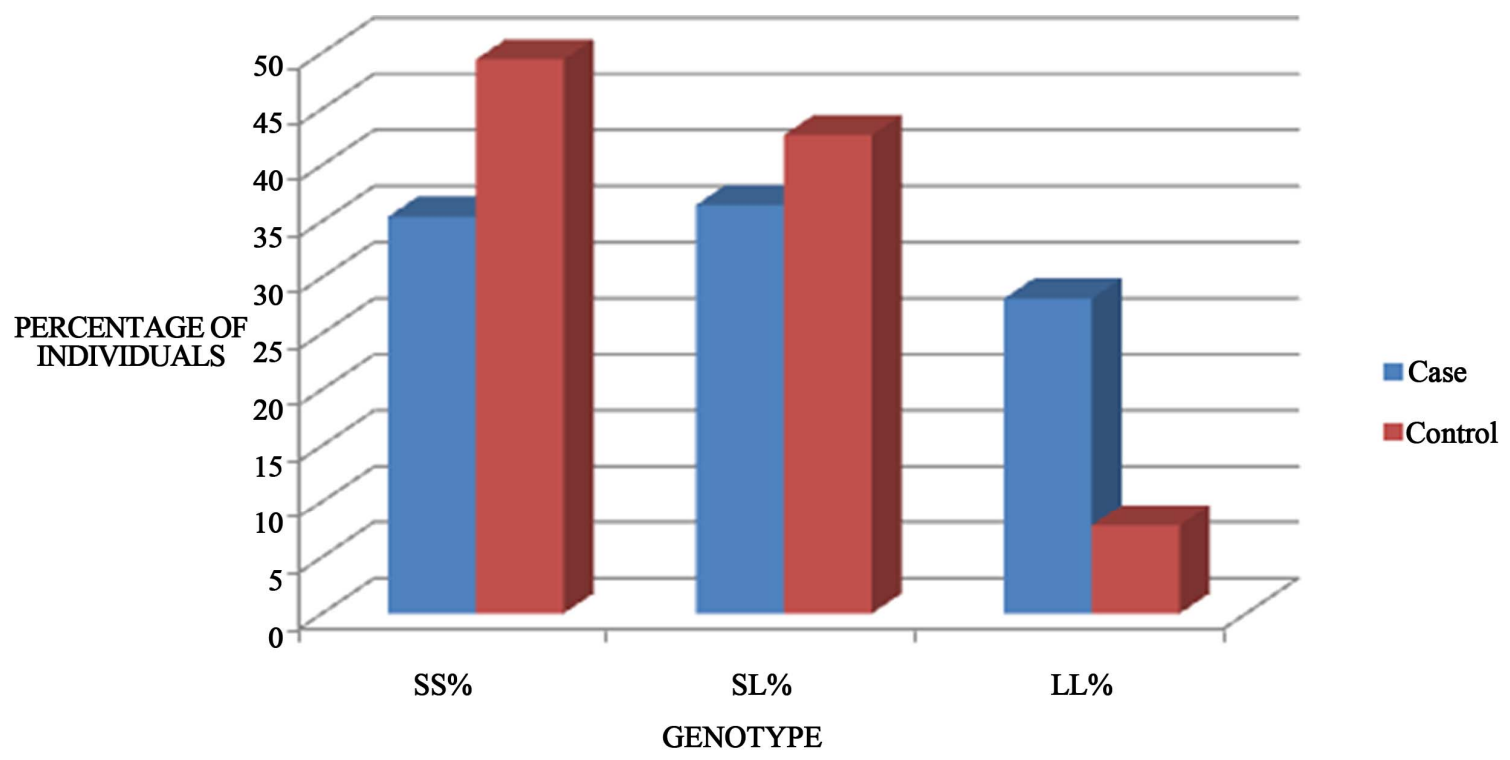

Figure 2. Distribution of GGN repeats of $A R$ gene in women with breast cancer.

Table 1. Comparison of frequencies of CAG and GGN homozygous repeats in cases and controls.

\begin{tabular}{|c|c|c|c|c|c|c|c|c|}
\hline \multirow{3}{*}{$\begin{array}{c}\text { REPEATS } \\
\text { Homozygous }\end{array}$} & \multicolumn{4}{|c|}{ CAG } & \multicolumn{4}{|c|}{ GGN } \\
\hline & \multicolumn{2}{|c|}{ Controls } & \multicolumn{2}{|c|}{ Cases } & \multicolumn{2}{|c|}{ Controls } & \multicolumn{2}{|c|}{ Cases } \\
\hline & $\mathrm{n}$ & $\%$ & $\mathrm{n}$ & $\%$ & $\mathrm{n}$ & $\%$ & $\mathrm{n}$ & $\%$ \\
\hline $13-13$ & - & & - & & 0 & & 1 & 2.00 \\
\hline $14-14$ & - & & 1 & 4.76 & - & & - & \\
\hline $15-15$ & 1 & 8.33 & 0 & 0.00 & - & & - & \\
\hline $17-17$ & 0 & 0.00 & 3 & 14.29 & - & & - & \\
\hline $18-18$ & 1 & 8.33 & 2 & 9.52 & - & & - & \\
\hline $19-19$ & 2 & 16.67 & 5 & 23.81 & - & & - & \\
\hline $20-20$ & 4 & 33.33 & 4 & 19.05 & 52 & 96.30 & 0 & 0.00 \\
\hline $21-21$ & 2 & 16.67 & 3 & 14.29 & 1 & 1.85 & 45 & 90.00 \\
\hline $22-22$ & 1 & 8.33 & 3 & 14.29 & 0 & 0.00 & 4 & 8.00 \\
\hline $23-23$ & - & & - & & 1 & 1.85 & 0 & 0.00 \\
\hline $26-26$ & 1 & 8.33 & - & & - & & - & \\
\hline Total & 12 & 13.48 & 21 & 21.87 & 54 & 60.67 & 50 & 52.63 \\
\hline $\mathrm{n}$ & 89 & & 96 & & 89 & & & \\
\hline
\end{tabular}

the median was taken to be 19 repeats (Mean \pm SD 19.13 \pm 2.76 ) for cases and 20 repeats (Mean \pm SD $19.40 \pm$ 2.72) for controls. In cases CAG allele $\leq 19$ was considered to be a Short (S) allele and allele $\geq 20$ was considered as a Long (L) allele and in control samples, CAG allele $\leq 20$ was considered to be a Short (S) allele and allele $\geq 21$ was considered as a Long (L) allele. Analysis revealed that $35.42 \%$ of cases and $49.44 \%$ of the controls had SS genotype. $36.46 \%$ of cases and $42.7 \%$ of the control samples were of SL genotype, whereas, very few LL genotype were present in controls $(7.86 \%)$ compared with case samples of $28.12 \%$ (OR, 4.58; 95\% CI, 10.61 - 1.98) (Figure 3).

For GGN repeat the median was 21 repeats (Mean \pm SD $21.00 \pm 1.56$ ) for cases and 20 repeats (Mean \pm SD $19.87 \pm 1.45$ ) for controls. In case samples the GGN repeat allele having $\leq 21$ repeats was taken to be a Short (S) allele and allele $\geq 22$ repeats was considered to be a Long (L) allele and in control samples, GGN repeat allele having $\leq 20$ repeats was taken to be a Short (S) allele and allele $\geq 21$ repeats was considered to be a Long (L) allele. Analysis revealed that $56.84 \%$ of cases and $73.03 \%$ of 
the controls had a SS genotype. $38.95 \%$ of cases and $24.72 \%$ of the control samples were of SL genotype, while LL genotype showed a very scarce distribution (Figure 4).

\section{Discussion}

We have investigated a potential link between the CAG and GGN short tandem repeats of the $A R$ gene in breast cancer in the South Indian women. The allelic frequencies of CAG in our control samples resemble those reported for Caucasian and Japanese populations [5,25,26]. In case of GGN repeat, alleles with 20,21 and 22 repeats were found most frequently in our study.
In CAG repeat, alleles with 20 repeats were observed in $13.02 \%$ of patients and $25.28 \%$ of controls (OR, 0.44 ; $95 \%$ CI, $0.26-0.75)$ which shows a significant correlation between case and control samples (p-value, 0.002).

Taking median as the cut-off we have categorised CAG allele into 2 types: S (short) and L (long), and hence the possible genotypes are-SS (Short-Short), SL (Short-Long) and LL (Long-Long). SS and SL genotypes do not show any significant correlation with respect to their $p$ value, whereas, the $p$ value of LL genotype (0.0004) was highly significant (OR, 4.58; 95\% CI, 10.61 - 1.98). This clearly indicates that long CAG alleles are highly associated with BC.

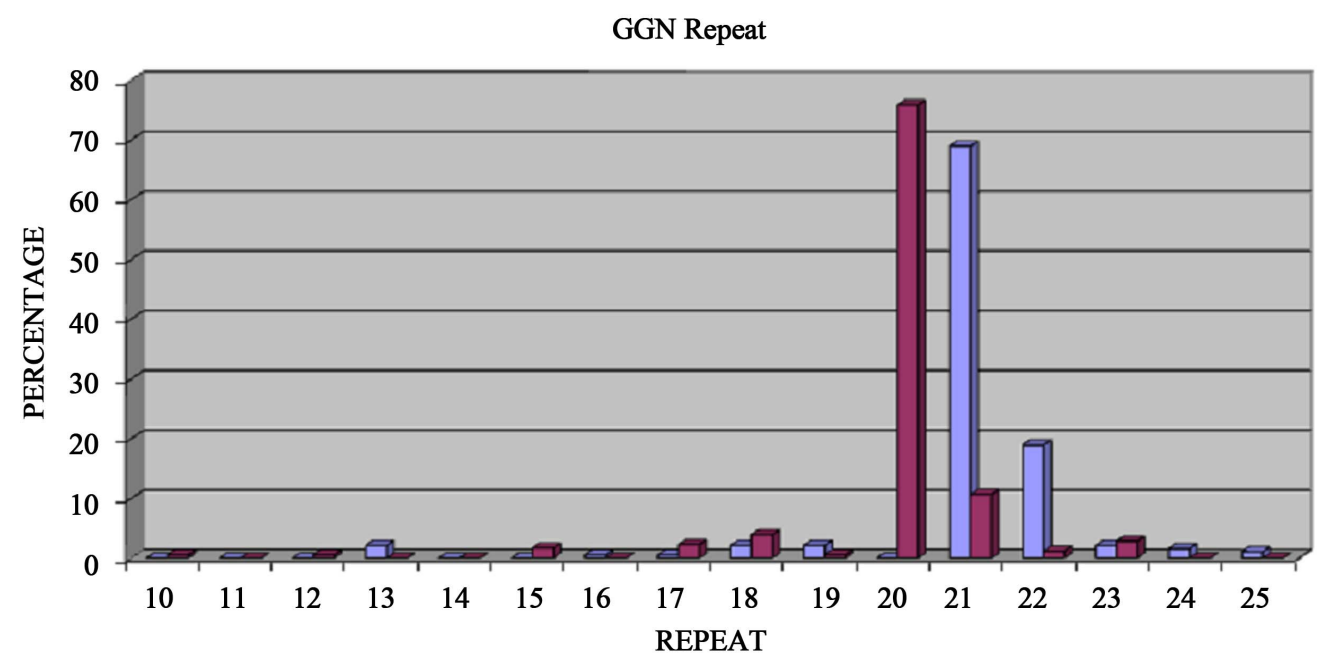

$\square$ case acontrol

Figure 3. Frequency (\%) of CAG repeats in case-control and their subgroups having the SS (short/short), SL (short/long) or LL (long/long) alleles.

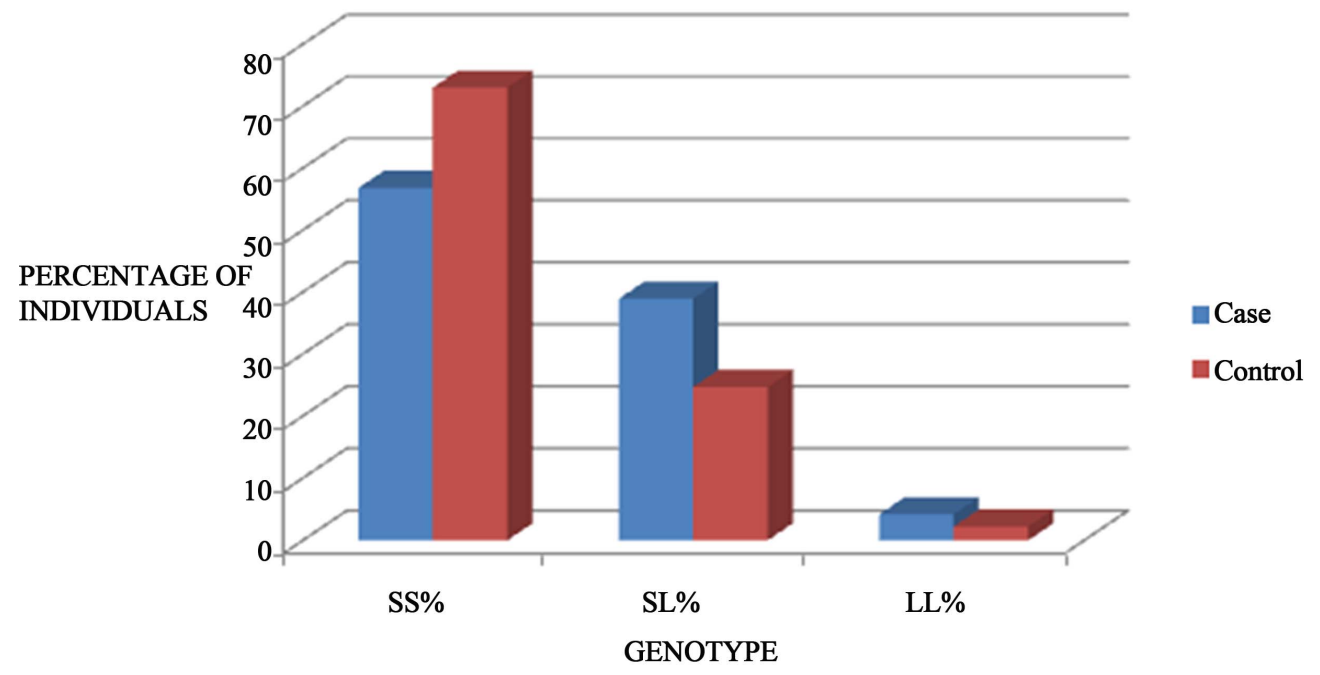

Figure 4. Frequency (\%) of GGN repeats in case-control and their subgroups having the SS (short/short), SL (short/long) or LL (long/long) alleles. 
In our study, controls showed a very high frequency of GGN alleles having 20 repeats $(96.3 \%)$, whereas, in case samples, $21(90 \%)$ and $22(8 \%)$ repeats had very high frequencies. Having categorised GGN genotypes into three, i.e. SS, SL and LL, it was observed that SS genotype was observed in $56.84 \%$ of cases and in $73.03 \%$ of controls (OR, 0.48; 95\% CI, 0.26 - 0.89; p value, 0.02). Our result shows that 20 homozygous repeats are protective whereas 21 homozygous repeat is affective in causing breast cancer. It is difficult to say if this one or two repeat shift can be a plausible risk factor or not. It requires a large population study to validate. But in our study none of the cases showed 20 repeats which clearly indicate that alleles having homozygous repeat 20 may be protective towards breast cancer in south Indian women.

Several case-control studies have investigated the relationship between CAG repeat length in the $A R$ and breast cancer risk but till date there have been only a few studies which have taken both CAG and GGN repeat length into consideration. A population based study of young women from USA found larger CAG repeat $(\geq 43)$ to increase the risk of breast cancer, whereas women with long GGN alleles and those with $\mathrm{a} \geq 33$ cumulative repeat size had a decreased risk of breast cancer [27]. A recent case-control study from Spain population showed CAG repeat $\geq 22$ and GGN $\geq 24$ to be associated with increased risk of breast cancer [5].

Our result in CAG repeat showed that patient having 20 repeat number and LL genotypes may have a risk of getting breast cancer. And GGN repeat $\geq 21$ showed a high risk of getting breast cancer. Our study is in accord with the previous two studies with respect to the CAG repeat, whereas, our result found no evidence to support the above mentioned study from USA in the case of GGN repeats which had described long GGN repeats to be protective [27].

The magnitude of the increased risk we observed with the $(\mathrm{CAG})_{\mathrm{n}}$ genotype was broadly similar to the findings of the population based study of breast cancer in USA and Spain, whereas it showed contradictory results with the data published by YouJin Hao et al. where they analyzed seven detailed genotyping case-control studies and found that a long CAG sequence has a protective effect on breast cancer [28].

Our results suggest that breast cancer risk might be likely related to androgenic activity, and longer CAG and GGN repeat may be associated with disease whereas, the shorter GGN repeat length genotype of $A R$ are protective. We observed a stronger and more consistent association between GGN repeat polymorphisms of the $A R$ gene and breast cancer.

Androgens are known to increase the risk of breast cancer by either acting as estrogen precursors or by direct action on breast cancer cells by binding to $A R$. Androgens have also been reported to act as antiproliferative agents in the presence of estrogens in some breast cancer cell lines. Both these effects of androgens are expressed through its binding to the $A R$ [6]. Hence, the effects of androgens are regulated by the androgen receptor. Therefore, any polymorphism, like that of the CAG and GGN tracts, might result in a variation in the $A R$ activity.

Presence of long (L) CAG allele reduces the transcriptional activity of the $A R$. Tertiary structure of $A R$ polyglutamine repeats has not been characterized [6]. Repeat length probably modifies the conformation of the protein affecting either the homodimer structure, which is required for the active form of $A R$, or the recognition and binding capability of $A R$ homodimer to the Hormone responsive elements (HREs). Hence affecting the transcription of the genes that are androgen dependent and therefore increasing the $\mathrm{BC}$ risk.

Similarly, the amount of the $A R$ protein is important. Because, the transcription machinery requires the continuous presence of androgen and androgen receptor and therefore the homodimers they form for the production of co-activators of transcription. Every time the gene is expressed, the transactivators (co-activators) are degraded by a ubiquitin pathway [29], that is, transcription is a cyclic process. Presence of long (L) GGN allele reduces the $A R$ protein yield. And, if the $A R$ protein yield is low, transcription machinery is again affected, increasing the risk of breast cancer.

Though it has to be ascertained whether the effects of $\mathrm{CAG}$ and GGN repeats on androgen action are independent or not, certainly the risk of $\mathrm{BC}$ increases if both together show any variation in repeat length since the presence of both long CAG and long GGN will result in both low levels of $A R$ and low transcriptional activity, multiplying the risk of $\mathrm{BC}$.

Also, the SS genotype has been observed in aggressive forms of cancer [30]. This further goes to show that the androgens and hence the $A R$ play a dual role-of protecting against cancer and also being one of the causes of cancer. Hence, there seems to be a balance between the dual roles of the androgen and its receptor, which in a way seems to be related to the repeat lengths of CAG and GGN tracts.

\section{Conclusion}

This is the first study addressing the association of CAG and GGN repeat length polymorphism in $A R$ gene in breast cancer in South Indian population. This finding may help explain the higher rate of breast cancer among South Indians, as well as their tendency to be diagnosed with more extensive disease risk. Our results showed a 
strong correlation between CAG and GGN repeat polymorphism and breast cancer. It requires a further study with a large population and different ethnic groups for the early prognosis of high risk patients of various ethnic populations and their respective management.

\section{Acknowledgements}

We are thankful to SVM, USA, for critically going through the manuscript. The financial assistance from Council of Scientific and Industrial Research, New Delhi, Government of India, is greatly acknowledged.

\section{REFERENCES}

[1] M. Ganapati, "India Has Some of the Highest Cancer Rates in the World," British Medical Journal, Vol. 330, No. 7485, 2005, p. 215. doi:10.1136/bmj.330.7485.215-c

[2] E. Deutsch, L. Maggiorella, P. Eschwege, J. Bourhis, J. C. Soria and B. Abdulkarim, "Environmental, Genetic and Molecular Features of Prostate Cancer," The Lancet Oncology, Vol. 5, No. 5, 2004, pp. 303-313. doi:10.1016/S1470-2045(04)01468-8

[3] J. F. Dorgan, C. Longcope, H. E. Stephenson Jr., R. T. Falk, R. Miller, C. Franz, L. Kahle, W. S. Campbell, J. A. Tangrea and A. Schatzkin, "Serum Sex Hormone Levels Are Related to Breast Cancer Risk in Postmenopausal Women," Environmental Health Perspectives, Vol. 105, Suppl. 3, 1997, pp. 583-585.

[4] T. S. Gao, M. Marcelli and M. J. McPhaul, "Transcriptional Activation and Transient Expression of the Human Androgen Receptor," The Journal of Steroid Biochemistry and Molecular Biology, Vol. 59, No. 1, 1996, pp. 9-20. doi:10.1016/S0960-0760(96)00097-0

[5] A. González, D. F. Javier, G. Rodriguez, B. Brito, M. A. Rodríguez, A. Cabrera, J. C. Díaz-hico, R. Reyes, A. Aguirre-Jaime and B. N. Díaz-Chico, "Increased Risk of Breast Cancer in Women Bearing a Combination of Large CAG and GGN Repeats in the Exon 1 of the Androgen Receptor Gene," European Journal of Cancer, Vol. 43, No. 16, 2007, pp. 2373-2380.

doi:10.1016/j.ejca.2007.07.001

[6] D.-C. B. Nicolás, R. F. Germán, A. González, R. Ramírez, C. Bilbao, A. C. de León, J. A. Aguirre, R. Chirino, D. Navarro and J. C. Díaz-Chico, "Androgens and Androgen Receptors in Breast Cancer," Journal of Steroid Biochemistry \& Molecular Biology, Vol. 105, No. 1-5, 2007, pp. $1-15$.

[7] S. N. Birrell, R. E. Hall and W. D. Tilley, "Role of the Androgen Receptor in Human Breast Cancer," Journal of Mammary Gland Biology and Neoplasia, Vol. 3, No. 1, 1998, pp. 95-103. doi:10.1023/A:1018730519839

[8] M. Brys, "Androgens and Androgen Receptor: Do They Play a Role in Breast Cancer?" Medical Science Monitor, Vol. 6, No. 2, 2000, pp. 433-438.
[9] D. J. Liao and R. B. Dickson, "Roles of Androgens in the Development, Growth, and Carcinogenesis of the Mammary Gland," The Journal of Steroid Biochemistry and Molecular Biology, Vol. 80, No. 2, 2002, pp. 175-189. doi:10.1016/S0960-0760(01)00185-6

[10] M. Langer, E. Kubista, M. Schemper and J. Spona, “Androgen Receptors, Serum Androgen Levels and Survival of Breast Cancer Patients," Archives of Gynecology and Obstetrics, Vol. 247, No. 4, 1990, pp. 203-209. doi:10.1007/BF02389545

[11] J. B. Adams, "Adrenal Androgens and Human Breast Cancer: A New Appraisal," Treat Breast Cancer Research and Treatment, Vol. 51, No. 2, 1998, pp. 183-188. doi:10.1023/A:1006050720900

[12] L. Bernstein and R. K. Ross, "Endogenous Hormones and Breast Cancer Risk," Epidemiologic Reviews, Vol. 15, No. 1, 1993, pp. 48-65.

[13] H. C. Shen and G. A. Coetzee, "The Androgen Receptor: Unlocking the Secrets of Its Unique Transactivation Domain," Vitamins \& Hormones, Vol. 71, 2005, pp. 301-319. doi:10.1016/S0083-6729(05)71010-4

[14] D. Navarro, O. P. Luzardo, L. Fernandez, N. Chesa and B. N. Diaz-Chico, "Transition to Androgen-Independence in Prostate Cancer," The Journal of Steroid Biochemistry and Molecular Biology, Vol. 81, No. 3, 2002, pp. 191201. doi:10.1016/S0960-0760(02)00064-X

[15] J. Beilin, E. M. Ball, J. M. Favaloro and J. D. Zajac, "Effect of the Androgen Receptor CAG Repeat Polymorphism on Transcriptional Activity: Specificity in Prostate and Non-Prostate Cell Lines," Journal of Molecular Endocrinology, Vol. 25, No. 1, 2000, pp. 85-96. doi:10.1677/jme.0.0250085

[16] I. Knoke, A. Allera and P. Wieacker, "Significance of the CAG Repeat Length in the Androgen Receptor Gene (AR) for the Transactivation Function of an M780I Mutant AR," Human Genetics, Vol. 104, No. 3, 1999, pp. 257261. doi:10.1007/s004390050945

[17] S. P. Huang, Y. H. Chou, W. S. Chang, et al., "Androgen Receptor Gene Polymorphism and Prostate Cancer in Taiwan," Journal of the Formosan Medical Association, Vol. 102, No. 10, 2003, pp. 680-686

[18] E. Esteban, N. Rodon, M. Via, E. Gonzalez-Perez, J. Santamaria, J. M. Dugoujon, F. E. Chennawi, M. Melhaoui, M. Cherkaoui, G. Vona, N. Harich and P. Moral, "Androgen Receptor CAG and GGC Polymorphisms in Mediterraneans: Repeat Dynamics and Population Relationships," Journal of Human Genetics, Vol. 51, No. 2, 2006, pp. 129-136. doi:10.1007/s10038-005-0336-7

[19] S. M. Gilbert, M. C. Benson and J. M. McKiernan, "Linkage Disequilibrium between the Androgen Receptor Gene CAG and GGC Repeats in the African-American Population," Current Urology Reports, Vol. 3, No. 3, 2002, 189-193. doi:10.1007/s11934-002-0063-y

[20] H. F. Sleddens, B. A. Oostra, A. O. Brinkmann and J. Trapman, "Trinucleotide (GGN) Repeat Polymorphism in the Human Androgen Receptor (AR) Gene," Human Molecular Genetics, Vol. 2, No. 4, 1993, p. 493.

doi: $10.1093 / \mathrm{hmg} / 2.4 .493$ 
[21] G. Rodriguez, C. Bilbao, R. Ramirez, O. Falcon, L. Leon, R. Chirino, O. Falcon Jr., B. P. Diaz, J. F. Rivero, M. Perucho, B. N. Diaz-Chico and J. C. Diaz-Chico, "Alleles with Short CAG and GGN Repeats in the Androgen Receptor Gene Are Associated with Benign Endometrial Cancer," International Journal of Cancer, Vol. 118, No. 6, 2006, pp. 1420-1425. doi:10.1002/ijc.21516

[22] M. P. Zeegers, L. A. Kiemeney, A. M. Nieder and H. R. Ostrer, "How Strong Is the Association between CAG and GGN Repeat Length Polymorphisms in the Androgen Receptor Gene and Prostate Cancer Risk?" Cancer Epidemiology, Biomarkers and Prevention, Vol. 13, No. 11, 2004, pp. 1765-1771.

[23] A. W. Hsing, I. Y.-T. Gao, G. Wu, X. Wang, J. Deng, Y.-L. Chen, I. A. Sesterhenn, F. K. Mostofi, J. Benichou and C. Chang, "Polymorphic CAG and GGN Repeat Lengths in the Androgen Receptor Gene and Prostate Cancer Risk: A Population-Based Case-Control Study in China," Cancer Research, Vol. 60, No. 18, 2000, pp. 51115116.

[24] A. Khattri, R. K. Pandey, N. J. Gupta, B. Chakravarty, M. Deendayal, L. Singh and K. Thangaraj, "CA Repeat and RsaI Polymorphisms in ERb Gene Are Not Associated with Infertility in Indian Men," International Journal of Andrology, Vol. 32, No. 1, 2007, pp. 1365-2605.

[25] R. A. Kittles, D. Young, S. Weinrich, et al., "Extent of Linkage Disequilibrium between the Androgen Receptor Gene CAG and GGC Repeats in Human Populations: Implications for Prostate Cancer Risk," Human Genetics, Vol. 109, No. 3, 2001, pp. 253-261.

\section{doi:10.1007/s004390100576}

[26] M. Sasaki, M. Kaneuchi, N. Sakuragi, S. Fujimoto, P. R. Carroll and R. Dahiya, "The Polyglycine and Polyglutamine Repeats in the Androgen Receptor Gene in Japanese and Caucasian Populations," Biochemical and Biophysical Research Communications, Vol. 312, No. 4, 2003, pp. 1244-1247. doi:10.1016/j.bbrc.2003.11.075

[27] N. M. Suter, K. E. Malone, J. R. Darling, D. R. Doody and E. A. Ostrander, "Androgen Receptor (CAG)n and (GGC)n Polymorphisms and BC Risk in a Population-Based Case-Control Study of Young Women," Cancer Epidemiology, Biomarkers \& Prevention, Vol. 12, No. 2, 2003, pp. 127-135.

[28] Y. J. Hao, R. Montiel, B. H. Li, E. Y. Huang, L. Zeng and Y. S. Huang, "Association between Androgen Receptor Gene CAG Repeat Polymorphism and Breast Cancer Risk: A Meta-Analysis," Breast Cancer Research and Treatment, Vol. 124, No. 3, 2010, pp. 815-820.

[29] Z. Nawaz and B. W. O'Malley, "Urban Renewal in the Nucleus: Is Protein Turnover by Proteasomes Absolutely Required for Nuclear Receptor Regulated Transcription?" Molecular Endocrinology, Vol. 18, No. 3, 2004, pp. 493499. doi:10.1210/me.2003-0388

[30] H. Yu, B. Bharaj, E. J. Vassilikos, M. Giai and E. P. Diamandis, "Shorter CAG Repeat Length in the Androgen Receptor Gene Is Associated with More Aggressive Forms of Breast Cancer," Breast Cancer Research and Treatment, Vol. 59, No. 2, 2000, pp. 153-161. doi:10.1023/A:1006356502820 